\title{
PV Improved Power Using Off-Normal Sun Tracking
}

\author{
Abdalla, Musa ${ }^{1} \&$ Abu Quba, Hanan ${ }^{2}$ \\ ${ }^{1}$ School of Engineering, The University of Jordan, Amman, Jordan \\ ${ }^{2}$ The University of Jordan, Jordan \\ Correspondence: Musa Abdalla, School of Engineering, Mechanical Department, The University of Jordan, \\ Amman 11942, Jordan, Tel: 962-6535-5000. E-mail: admin@mechatronix.us
}

Received: May 27, 2017

Accepted: June 8, 2017

Online Published: October 31, 2017

doi:10.5539/mas.v11n11p66

URL: https://doi.org/10.5539/mas.v11n11p66

\begin{abstract}
Harvested Power from two axes tracking Photovoltaic modules is analyzed and investigated for the objective of enhancing its reduced efficiency in hot to moderate climates. A novel proposed natural cooling of the modules that depends on optimizing the PV different dynamical models is presented. The optimized PV orientation angles for the tracking system revealed that exact normality of the sun rays over the PV module may not be the best setup! The wind speed and direction over the PV impacts the collector's temperature and consequently the PV efficiency. Finally, the work was verified and validated using real collected data from a weather station in Jordan.
\end{abstract}

Keywords: PV Optimization, PV Cooling, MPP, Sun Tracking System

\section{Introduction}

\subsection{Overview}

The instabilities in today's oil and gas markets, the concern about their impacts on the environment and doubts in their prolonged existence has motivated engineers and scientists to search for alternative fuels. Many alternative sources of energy were identified and analyzed for their effectiveness and consequences. But the man's look to the sun in the sky stayed the same. The expectation and hopes on utilizing the vivid sun rays kept growing. Renewable resources are the best solution for solving the crisis of energy around the world, through providing a clean energy.

Even-though the solar technology still premature, but the outcomes are very promising. With low photovoltaic efficiencies, one needs to optimize and tune sensitive parameters to scrutinize seeking the best. In this study, photovoltaic energy is highlighted, which is considered one of the most sustainable renewable energy resources. Luckily, in Jordan most of the areas of the Kingdom are covered with reasonable irradiation period exceeding (300) days per a year, owing this to the location of the Kingdom on the equator.

One of the main disadvantages of the photovoltaic module energy is the low efficiency, so all of the studies on this subject have focused on investigating possibilities of improving the performance of the photovoltaic cells the optimization the PV typically was based on the analytical model and the vertical using experimental work.

The performance of a solar cell is highly influenced by its orientation and its tilt angle with the horizon. This is because both the orientation and tilt angle change the solar radiation reaching the surface of the PV. Computer simulations may be used to analyze and study the effects of many environmental parameters over the PV performance (Villalva, Gazoli \& Filho, 2009; Ramos, Campayo, Zamora, Larrañaga, Zulueta \& Puelles, 2010).

The performance of PV model depends on the materials of the model, environmental parameter, and the controlling of the model, which ultimately determine the efficiency of the total system of PV and the output power. Therefore, the three photovoltaic models (PV model, efficiency model, and heat transfer) models must be optimized properly to give in total maximum efficiency, maximum power with minimum overall losses. This will not be achieved by making the solar cell perpendicular with the sun, where we are in this case, increase the amount of falling light on the cell and concurrently increase the cell temperature, so the efficiency and output power will reduce. Both the electrical efficiency and the output power of PV module were found to depend linearly on the operating temperature and decreasing with cell surface temperature (Skoplaki \& Palyvos, 2008).

This dilemma may be minimized by optimization and control of the module essential and related parameters. The system optimization could be accomplished by controlling the parameters affecting the performance of the 
three models (PV model, efficiency model, and heat transfer) to give maximum tracking power (MTPP) point by controlling the tilt and orientation angles to produce an optimal output power and maximum efficiency.

The performance of a solar cell is highly influenced by its orientation and its tilt angle with the horizon. This is because both the orientation and tilt angle change the solar radiation reaching the surface of the collector and at the same time impacts the amount of unwanted heat transfer that will lead to elevated modules' temperatures.

\subsection{Sun Tracking Systems}

PV modules still have relatively low conversion efficiency; therefore, controlling maximum power point tracking (MPPT) for the solar array is essential in a PV system. Solar tracking systems can be used in industrial installations where higher efficiency required (Chandrakar \& Tiwari, 2013). The total amount of power generated by a PV depends on the operating voltage of the array. A PV's maximum power point (MPP) varies with solar insulation and temperature. The intrinsic photovoltaic V-I and V-P characteristic curves specify a unique operating point at which maximum possible power is delivered as shown in Figure 1.

Tracking systems are designed in a way to track the solar azimuth angle on a single axis or to track the solar azimuth and tilt angle on two axes which is known as a two axis tracking system. Solar tracking is not a new concept, though it is a considerably new concept compared to PV cells.

Basically, there are many factors that must be taken into consideration to design an effective solar tracker. Factors such as cost, reliability, efficiency, and accuracy in positioning are essential design elements in order to outperform a well-positioned stationary PV panel. Many design options for a solar tracking system must be taken into careful consideration to ensure that the system is maximizing its output from tracking the sun.

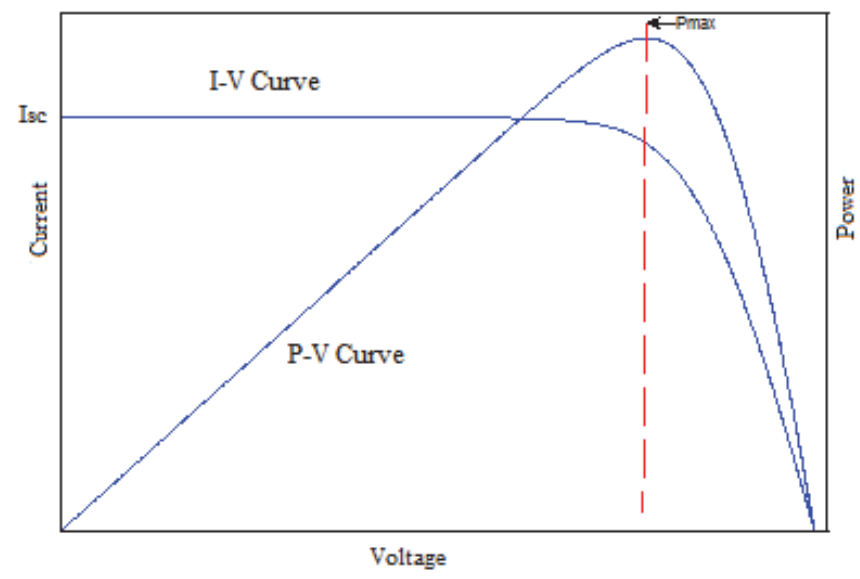

Figure 1. VI / VP Characteristic Curves: MPP

\subsection{Tracking System Types}

In general, there are two main groups that can categorize solar trackers: single or dual axes trackers. The first type of active solar collecting is single axis tracking. This is will result in a greater power output than stationary or fixed PV panels, but it is also more costly to design and implement. Single axis solar trackers can either have a horizontal or a vertical axis. The horizontal type is used in regions near the equator where the sun gets very high at noon, thus not having to adjust to vertical changes so much as horizontal changes, which is depicted in Figure 2.a (Planning and Installing Photovoltaic Systems 2008).

The second type of active solar collecting is dual axis tracking. This gives much greater power output than a stationary PV panel and single axis tracker but is also the most costly and most complicated to design. Dual axis solar trackers have both a horizontal and a vertical axis and thus they can track the sun's apparent motion virtually anywhere in the sky no matter where it is positioned on earth, as shown in Figure 2.b.

\section{Methods}

Sun tracking may increase the power output for PV solar power plants depending on the geographic location. Typically, a single axis tracker will increase power output by $26 \%$, while a dual axis tracker increases power by $32 \%$. Single axis trackers follow the sun from east to west, while the two axes trackers track the sun altitude (up/down) as well. With a fixed solar panel, there is significant power lost during the day because the panel is not kept perpendicular to the sun's rays. A tracking system persists to keep the angle of incidence within a 
certain margin and would be able to maximize the power generated. A stationary or fixed PV panel will observe a modest efficiency under ideal conditions, while solar tracking has been known to potentially double that efficiency under ideal conditions (Mousazadeh et al. 2009; Midya, Kerin, Turnbull, Reppa \& Kimball, 1996).
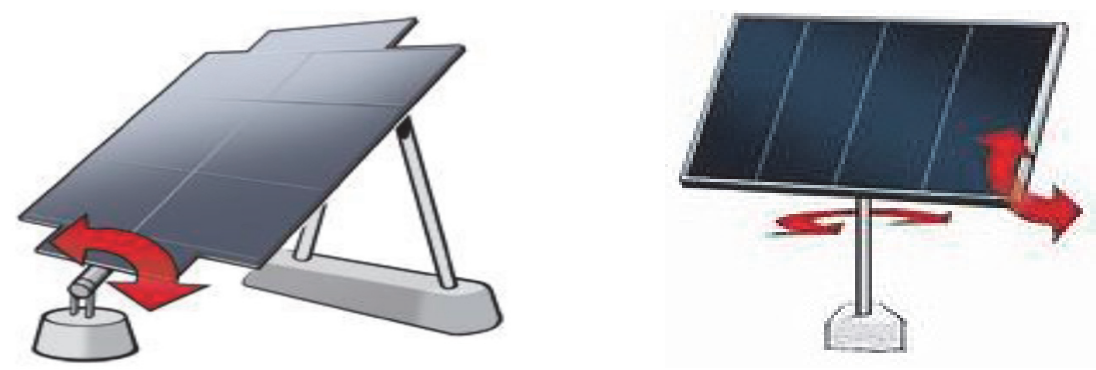

Figure 2. Sun Tracking Systems

In tracking systems, to make the calculation of PV angles, one needs to consider the sun's position relative to the collector's surface in terms of the incidence angle: $\theta$. The sun's angle of incidence is the angle between the solar rays and the surface normal. In order to evaluate the angle of incidence we need to specify the direction of the surface normal. This is done in terms of the surface tilt angle: $\Sigma$ and the surface azimuth angle: $\phi_{c}$. These angles are defined in Figure 3. The surface tilt angle is the angle between the surface normal and vertical. The surface azimuth angle is the angle between south and the horizontal projection of the surface normal. The same sign convention is used for the surface azimuth angle as is used for the solar azimuth angle, i.e. $\phi_{\mathrm{s}}$ is negative for a surface that faces east of south and positive for a surface that faces west of south. Figure 3 depicts the used notation for the two axes tracking systems.

Conventional two axes tracking systems position the tilt angle and the collector azimuth angle to collect the maximum power point at every hour. The incident angle is reported as the most effective parameter that affects the PV collected power. But it elevates the PV collector's surface temperature $\left(\mathrm{T}_{\mathrm{c}}\right)$ due to the direct exposure that results from the continuous tracking and seeking of the sun. The dramatic increase in the $\left(\mathrm{T}_{\mathrm{c}}\right)$ temperature, especially during the summer times, compromises the PV efficiency. This problem may be resolved by lowering the collector's surface temperature using active or passive cooling techniques.

In certain regions, one may take advantage of the air forced convection that occurs over the PV module. An effective two axes tracking system need to trade part of the incident angle to increase the amount of air convection cooling effect (i.e. wind speed $\mathrm{V}_{\mathrm{w}}$ and direction orientation) rather than positioning the PV normal to the sun rays at all times.

Sun tracking systems work efficiently in tracking the MPP under varying environmental conditions; while PV fixed systems collect less power under the same conditions. Solar systems that track the changes in the sun's trajectory over the course of the day collect a far greater amount of solar energy and consequently generate significantly higher output powers.

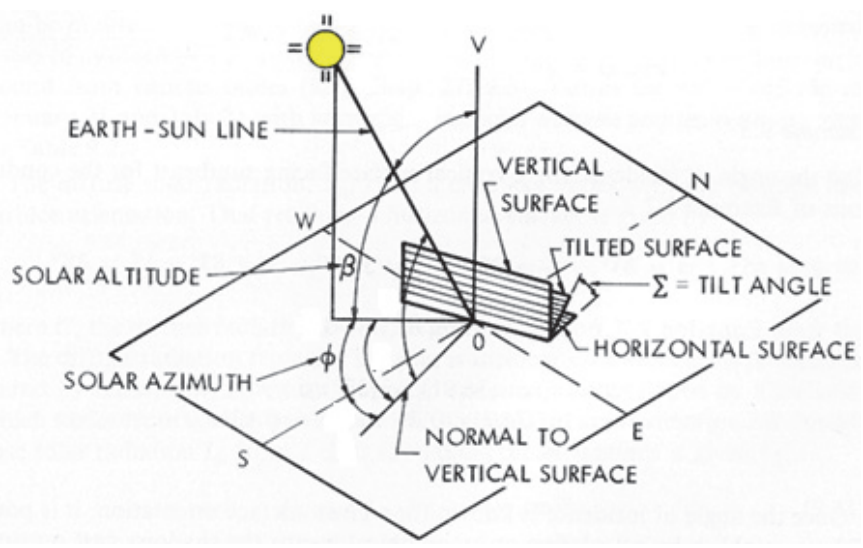

Figure 3. Definitions of Needed Tracking Angles

In Jordanian regions, it is observed that tracking systems increase the harvested energy, it achieves an overall power collection efficiency increase from only $19 \%$ for a fixed system to over $30 \%$ for the same module on the 
tracking system during summer time. Table 1 illustrates a comparison between a fixed and a tracking system.

Table 1. Sun Received Energy (Wh) for Photovoltaic Systems

\begin{tabular}{lccc}
\hline Type & Fixed panel & Two axis tracker & Cos(theta)=1 \\
\hline 10 January & 30.6 & $\mathbf{1 1 0 . 3}$ & 110.9 \\
$1^{\text {st }}$ April & 1511 & $\mathbf{2 8 3 1}$ & 2921 \\
$1^{\text {st }}$ July & 1403 & $\mathbf{3 7 8 3}$ & 3932 \\
\hline
\end{tabular}

\subsection{Effect of Wind Speed/Direction on PV Performance}

Direct measurements of the cell temperature for most PV installations are not available. Therefore, it is desirable to parameterize the physical relation between the PV cell temperature, irradiance and relevant meteorological parameters, such as wind. The wind is the most important parameter that influences the cell temperature. The commonly used standard approach to model the cell temperature is based on ambient air temperature and in-plane irradiance measurements but it does not include the impact of wind speed and direction on the cell temperature (Skoplaki \& Palyvos, 2008).

The cell temperature of a PV module is dependent on the wind speed (see equation 1), its direction, the solar irradiation and ambient temperature. The wind speed effect is directly tied to the cooling of a PV module via air convection heat transfer. It is reported that even for very low wind speeds, the limited cooling effect still increases the convection heat transfer which decreases the module temperature based on the mounting structure for the PV module or system (Quaschning, 1996). On the other hand, the designer should consider the wind speed and its direction effects on the PV mounting structure, because it directly impacts the mechanical behavior of the PV system.

$$
T_{c}=T_{a}+\left[\frac{G_{T}}{G_{T, N O C T}}\right]\left[\frac{9.5}{5.7+3.8 V_{w}}\right]\left(T_{N O C T}-T_{a, N O C T}\right)\left(1-\eta_{\mathrm{m}, \mathrm{ref}}\right)
$$

Where:

NOCT: The nominal operating cell temperature

$G_{T}$ : Solar radiation flux (irradiance) on module plane $(\mathrm{W} / \mathrm{m} 2)$

$V_{w}$ : Wind speed at monitored surface $(\mathrm{m} / \mathrm{s})$

$\alpha$ : Solar absorbance of PV layer.

$\tau$ : Solar transmittance of glazing.

$\eta_{\mathrm{c}}$ : the efficiency of the module in converting incident radiation into electrical energy.

Furthermore, the PV cell temperature is a function of physical characteristic and environmental conditions, and it has a linear inversely proportional to the efficiency cell and the power output of PV module, as both the electrical efficiency and the power output of PV module are decreasing linearly with operating temperature, which is represented by equations ( 1 and 2 ).

$$
\begin{gathered}
\eta_{c}=\eta_{\text {ref }}\left(1+\beta\left(T_{c}-T_{a}\right)\right) \\
\eta_{\max }=\frac{P_{\max }}{G_{T} A_{C}}
\end{gathered}
$$

Where:

$P_{\text {max }}$ : Rated Maximum Power (W)

$A_{c}$ : Projected area of the solar module

$\beta$ : The temperature coefficient $=-0.0045 \mathrm{~W} / \mathrm{m} 2 . \mathrm{C}$

$\eta_{\max }$ : The maximum efficiency of the PV module. 
Figure 4 illustrates the heat transfer in the PV cell, which is clearly dependent on the convection, conduction, and radiation heat transfer mechanism. It is reported that convective heat transfer is maximized when the wind impinges on the PV cells in a plane perpendicular to the array (Wen, 1982).

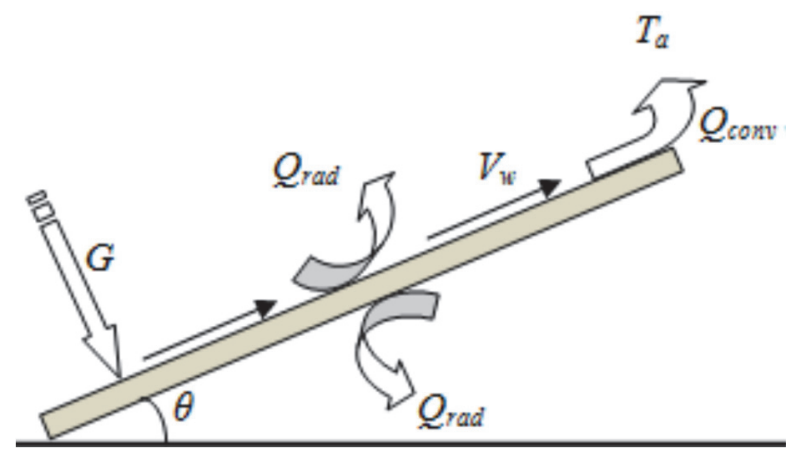

Figure 4. Heat Exchanges in an Unglazed PV Cell

The cell temperature can be calculated by the equation (3).

$$
T_{c}=T_{a}+\omega\left(\frac{0.32}{8.91+2 V_{F}}\right) G
$$

While the convective heats transfer by wind affecting the PV cell surface may be expressed as

$$
\begin{gathered}
Q=\dot{m} c_{p} \frac{d T_{c}}{d t} \\
\dot{m}=\rho V_{F} A
\end{gathered}
$$

Where:

$Q$ : radiative heat transfer $\left(\mathrm{W} / \mathrm{m}^{2}\right)$.

$V_{F}$ : free stream velocity, at a height of $10 \mathrm{~m}$ above the surface.

$\omega$ : mounting coefficient, which is for Flat roof $=1.238$.

$d m / d t$ : mass flow rate, $\mathrm{kg}$.

$c_{p}$ : specific heat, $\mathrm{k} \mathrm{J} / \mathrm{kg}$. $\mathrm{C}^{\mathrm{o}}$, which 0.91 for Aluminum.

$\rho:$ air density $=1.225 \mathrm{~kg} / \mathrm{m} 3$.

$A$ : projected area of the solar module.

\subsection{Photovoltaic System Modeling}

In order to simulate the PV complete process, one needs to consider all the models that affect the PV functionality. The Different models of PV are applied to express of the behavior of PV cell, which simply consists of p-n junction fabricated in a semiconductor usually a made of silicon. The overall module of PV considered in this thesis is consisting of three models: Electrical, Heat Transfer, and Efficiency.

The solar cell is the basic unit of a photovoltaic module, which transfers the irradiation into an electric current. The simplest equivalent circuit model of a PV cell is a current source in parallel with a diode, where the output of the source is directly proportional to the light falling on the cell. Figure 5 depicts the solar cell equivalent circuit. 


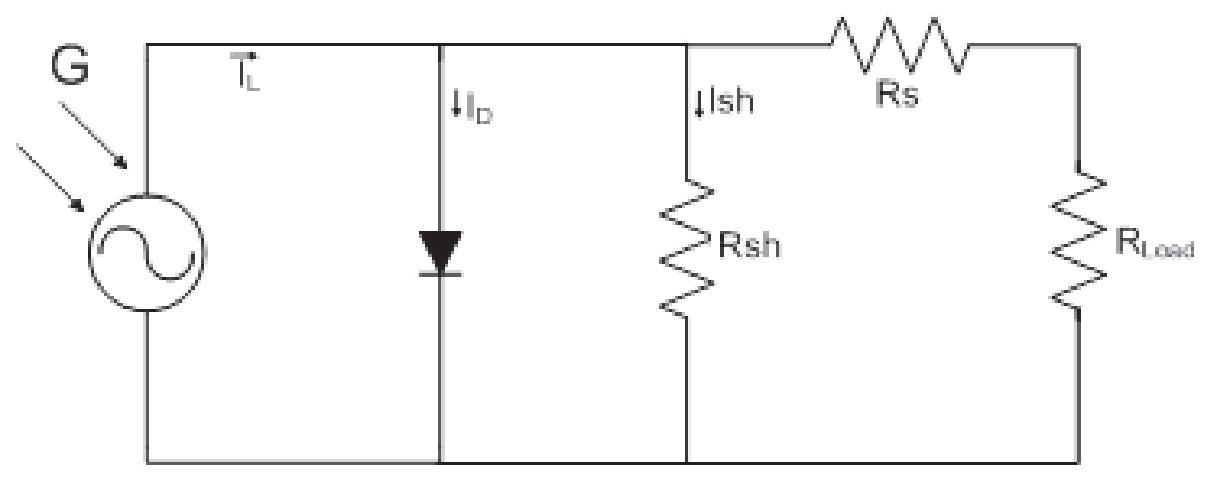

Figure 5. Solar Cell Electrical Equivalent Circuit

One of the main critical issues that hinder the advances in the spread of the photovoltaic technology in hot climates is the nominal operating cell temperature (NOCT). The PV cell temperature is a function of physical characteristic and environmental conditions, and it is a linear inversely proportional to the cell efficiency and the power output of PV module, as both the electrical efficiency and the power output of PV module are decreasing linearly with operating temperature (Duffie, 2013; Christiana, 2012). The nominal operating cell temperature (NOCT) is defined as the cell or module temperature that is reached when the cells are mounted in their normal way at a solar radiation level of $800 \mathrm{~W} / \mathrm{m} 2$, a wind speed of $1 \mathrm{~m} / \mathrm{s}$, an ambient temperature of $20 \mathrm{C}^{\circ}$, and no-load operation.

Consulting the PV heat transfer model reveals that the cell temperature resulting from the convection and conduction for the PV cell is directly affecting the performance of the photovoltaic system. Consequently, the overall module PV design should consider the optimization of three models: PV electrical, heat transfer and efficiency models. Typically, environmental parameters such as ambient temperature, wind speed, and irradiation impacts the PV harvested useful power, which is also varying throughout the year.

In this work, the three models of a PV Cell (electrical, heat transfer, and efficiency models) has been implemented using a Matlab program/ Simulink, and the module positioning parameters angles were optimized for best operating points. Maximum search techniques were utilized to seek the optimum point.

\subsection{PV Test Bed}

A Mono crystalline technology based PV model type F330 Solar Module, Manufactured by sun Edison- USA was considered to verify and validate the results of this project. All the required data for simulation and testing is based on shams Maan Substation located in the southern part of Jordan.

Ma' an is located in the southern part of Jordan, at a latitude of $30.17 \mathrm{o} \mathrm{N}$ and a longitude of $35.82 \mathrm{o} \mathrm{E}$ (Jones \& Underwood, 1999). Altitude of Ma'an is around 1000m over the sea level. Ma'an is considered one of the best sites in Jordan because it is located within the "solar belt" and it harvests a very good solar irradiation (National Energy research Center (NERC)- Jordan, Feb 2012). Actually, Ma'an is one of the highest solar irradiation areas in Jordan and it has low values of diffuse irradiation, and it has wide flat lands which is suitable for large scale PV plants. These characteristics attracted many governmental and private large projects to be constructed at Ma'an region.

The F330 Solar Module provides 330 watts of nominal maximum power and has 72 series connected Mono crystalline silicon cells. The key specifications of the PV module are summarized Table 2.

The model of the PV module was implemented using a Matlab program/Simulink. The program and simulation calculate the current I, using the typical electrical parameters of the module (ISC, VOC), and the variables Voltage, Irradiation (G), and Temperature (T). 


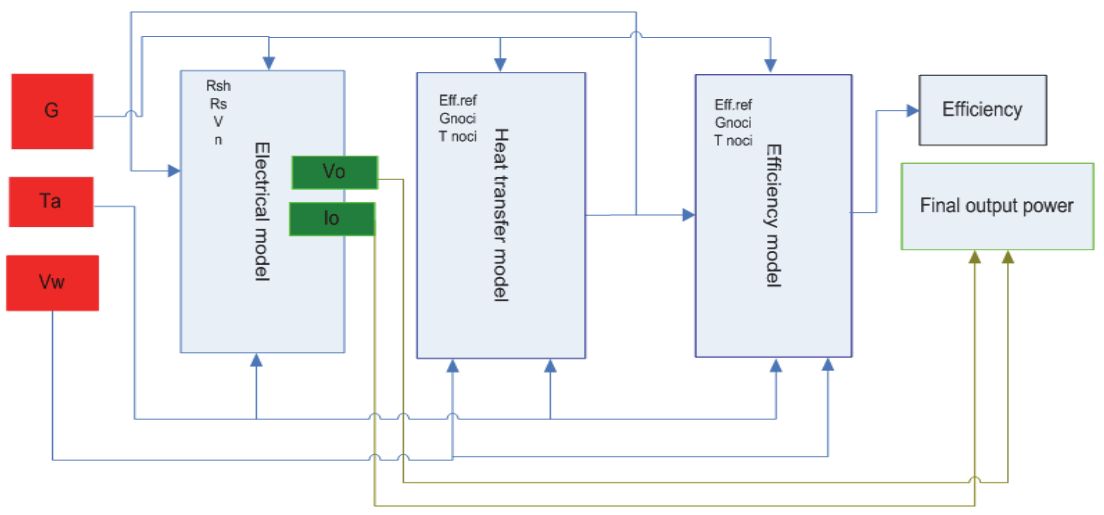

Figure 6. Simulink Modeling of the PV Module

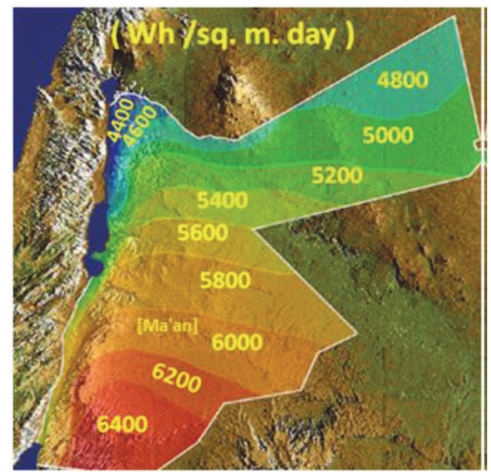

Figure 7. Jordan Daily Average Solar Radiation (National Energy research Center (NERC)- Jordan, Feb 2012)

Table 2. Physical Parameters (SunEdison Silvantis modules, F330 ByC Data Sheet_09 2013)

\begin{tabular}{ll}
\hline Cell-Type & Solaicx, CCz Mono-crystalline \\
\hline Number of Cells & 72 \\
Nominal Operating Cell Temperature $(\mathrm{NOCT})\left({ }^{\circ} \mathrm{C}\right)$ & $47.0 \pm 2$ \\
Temperature Coefficient of Pmax $\left(\% /{ }^{\circ} \mathrm{C}\right) \beta$ & -0.45 \\
Temperature Coefficient of Voc $\left(\% /{ }^{\circ} \mathrm{C}\right)$ & -0.33 \\
Temperature Coefficient of Isc $\left(\% /{ }^{\circ} \mathrm{C}\right)$ & 0.05 \\
Operating Temperature $\left({ }^{\circ} \mathrm{C}\right)$ & -40 to +85 \\
Maximum System Voltage $(\mathrm{V})$ & $1000(\mathrm{UL} \& \mathrm{IEC})$ \\
Limiting Reverse Current $(\mathrm{A})$ & 9.10 \\
Maximum Series Fuse Rating $(\mathrm{A})$ & 15 \\
Power Selection $(\mathrm{W})$ & $-0 /+5$ \\
\hline
\end{tabular}

Table 3. Electrical Characteristics* Model \# F330 (SunEdison Silvantis modules, F330 ByC Data Sheet_09 2013)

\begin{tabular}{l|l}
\hline Rated Maximum Power Pmax (W) & 330 \\
Open-Circuit Voltage Voco (V) & 46.2 \\
Short Circuit Current Isco (A) & 9.28 \\
Module Efficiency (\%) & 16.9 \\
Maximum Power Point Voltage Vmpp (V) & 37.7 \\
Maximum Power Point Current Impp (A) & 8.77 \\
\hline Module Dimensions(Ac) (mm) & 990 by 1,976 \\
\end{tabular}

\section{Results and Discussions}

To study the effect of wind speed and direction, we had implemented equations (1-3) in the original Matlab program. The direction of the wind was taken from Maan environmental readings and it was reference to the two 
axes direction recorded notation without wind effect. After that the program tracked the cell with air speed and direction to arrive at the desired orientation that reduces cell temperature.

Graphical representation of the maxima was generated using the off-line measurements, where clearly a maximum power generated at off sun ray normality conditions. Figure 8 shows the maximum power point obtained in three cases: fixed system, tracking system with $\cos (\theta)=1$, and tracking cooling system for summer date (day $n=182$ ).

Therefore the wind direction and wind speed affected of lowering the cell operating temperature, thereby resulting in a potential gain in efficiency. From the previous discussion, it is evident that wind speed and wind direction have a significant influence on the PV cell efficiency. The results were based on the simple case of parallel wind flow over flat surfaces.

It is of interest to appreciate the effect of variation in wind flow direction on PV efficiency. From the Table 4 clear the tilt angle and azimuth angle in case of cooling system and tracking system, where in case of cooling system the two tracking angles are slightly modified causing a change into wind angle which faced the cell to decrease its temperature and cooling the cell.
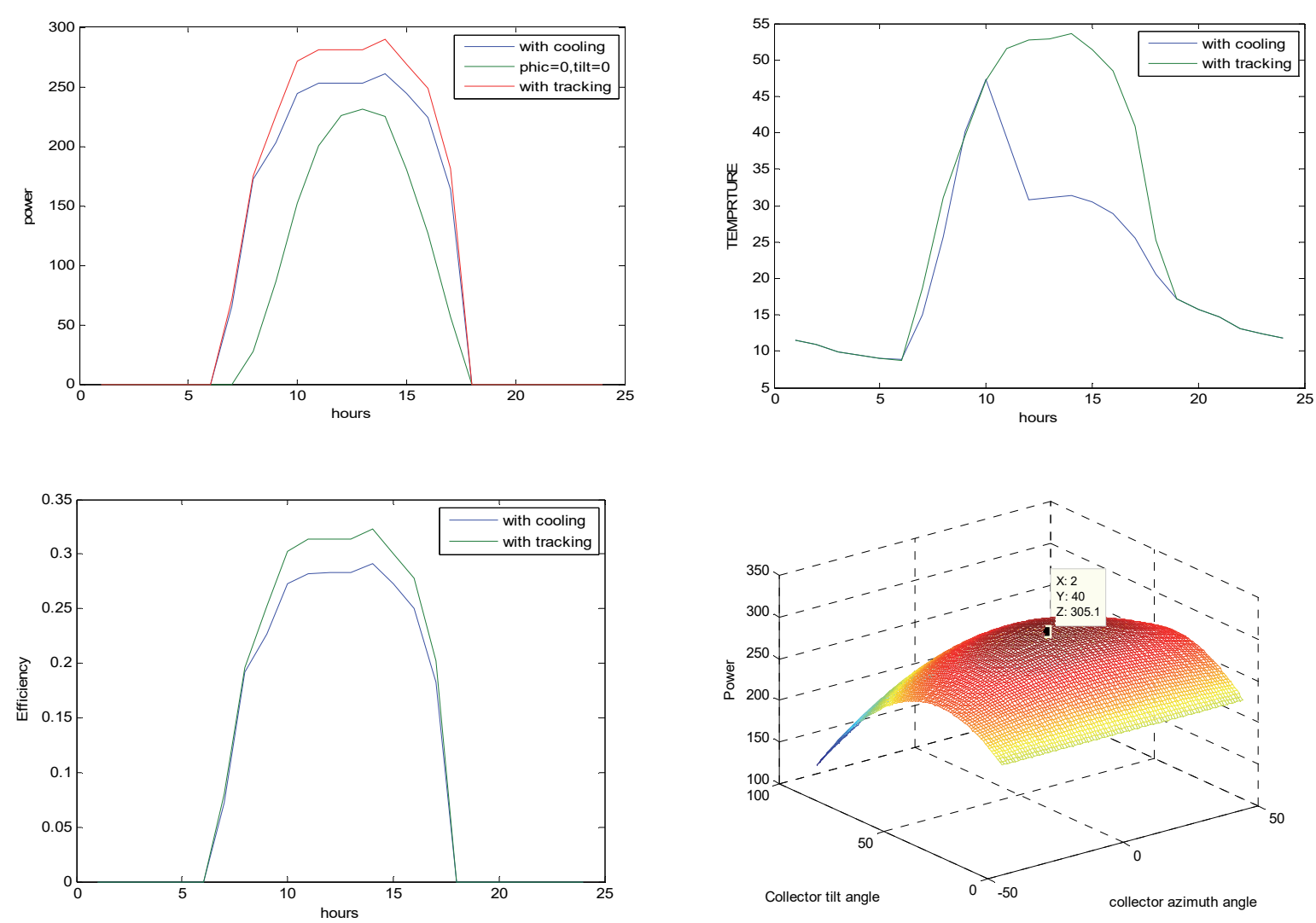

Figure 8. Maximum Power with Cooling on 1st of April, Vmpp (V) = (37.7 V) During Dynamic Weather

Table 4. The Received Energy (Wh), for Photovoltaic Systems with Wind Effects

\begin{tabular}{lccc}
\hline Type & Fixed panel & With cooling & Two axis tracker \\
\hline 10 Jan. & 30.6 & $\mathbf{1 0 0 . 4}$ & 111.8 \\
$1^{\text {st }}$ April & 1512 & $\mathbf{2 3 3 6}$ & $\mathbf{2 5 7 5}$ \\
$1^{\text {st } J u l y ~}$ & 1410 & $\mathbf{2 7 1 6}$ & 2788 \\
\hline
\end{tabular}

The results in Tables 4 and 5 illustrate the effect of the natural cooling air, which is efficient in summer days, where the ambient temperature is high. But the cell temperature increase (i.e. it can reach $80^{\circ} \mathrm{C}$ ) which in turn reduces the efficiency. Apparently, by changing the angles of tracking system to be aligned with air direction, one can reduce the cell temperature, causing sufficient increasing in efficiency, but it also lessens irradiance. 


\section{Conclusions}

Photovoltaic module system performance is analyzed for the objective of recovering its design power in hot climates. The work assumed a two axes sun tracking system is mounted on the PV module.

Direct sun exposure that is intentionally regulated by the sun tracker results in elevating the PV module cell temperatures, which in turn it reduces the PV module efficiency.

Off sun rays normality proven to recover the PV efficiency without compromising it's generated power. This was successfully achieved by orienting the PV in an optimized orientation to take advantage of the natural wind draft or gust over the PV module. Another advantage of avoiding running continuously on extreme cell surface temperatures during summer times is the prolonged life time of the cell (i.e. fewer degradation rates).

We recommend looking into on /lining optimization techniques that automatically seek the Maxima in the neighborhood of the conventional sun trackers operating point (i.e. normality). Measurements of the wind gust speed and direction are needed by the optimizer algorithm. Typically, the results are passed for the two axes servo motors for orienting the PV module in the newly optimized operating point.

\section{Acknowledgments}

This work was in partial supported by the Scientific Research Center, the University of Jordan.

\section{References}

Chandrakar, A., \& Tiwari, Y. (2013). Optimization of solar power by varying tilt angle/Slope, international Journal of emerging technology and advanced engineering, Vol. 3.

Christiana, H. (2012). Pvcdreom, Jan 2012. Retrieved from http://pveducation.org/pvcdrom

Duffie, J. (2013). Solar Engineering of Thermal Processes, Fourth Edition, Page 758.

Jones, A., \& Underwood, C. (1999). A thermal model for photovoltaic systems, Solar Energy, 70(4), 349-359.

Midya, P., Kerin, P. T., Turnbull, R. J., Reppa, R., \& Kimball, J. (1996). Dynamic Maximum Power Point Tracker for Photovoltaic Applications. Proceedings of the IEEE Power Electronics Specialists Conference, PESC, 2, 1710-1716.

Mousazadeh, H. et al. (2009), A review of principle and sun tracking methods for maximizing solar systems output. Renewable and Sustainable Energy Reviews, 13(2009), 1800-1818.

National Energy research Center (NERC)- Jordan, Feb 2012. Retrieved from http://www.nerc.gov.go

Planning and Installing Photovoltaic Systems (2008). A guide for installers, architects and engineers", Deutsche Gesellschaft für sonnenenergie (DGS LV Berlin BRB), 2008. Retrieved from http://www.earthscan.co.uk

Quaschning, D. I. V. (1996). Simulation der Abschattungsverluste bei solarelektrischen Systemen, Berlin.

Ramos, H., Campayo, M., Zamora, B., Larrañaga, L., Zulueta, G., \& Puelles, P. (2010). Modeling of a Photovoltaic Module, International Conference on Renewable Energies and Power Quality (ICREPQ'10): Spain.

Skoplaki, E., \& Palyvos, J. (2008). On the temperature dependence of photovoltaic module electrical performance, a review of efficiency/power correlations, Solar Energy, 614-624.

Skoplaki, E., \& Palyvos, J. (2008). Operating temperature of photovoltaic module, a survey of pertinent correlations, IEEE, Renewable Energy, 23-29.

SunEdison Silvantis modules, F330 ByC Data Sheet_09 2013. Retrieved from http://www.SunEdisonSilicon.com

Villalva, M., Gazoli, J., \& Filho, E. (May 2009). Comprehensive Approach to Modeling and Simulation of Photovoltaic Arrays". IEEE Transaction on Power Electronics, 24(5), 1198-1204.

Wen, L. (1982). An Investigation of the Effect of Wind Cooling on Photovoltaic Arrays, Report DOE/JPL 1012-69, JPL, Pasadena, California.

\section{Copyrights}

Copyright for this article is retained by the author(s), with first publication rights granted to the journal.

This is an open-access article distributed under the terms and conditions of the Creative Commons Attribution license (http://creativecommons.org/licenses/by/4.0/). 